\title{
Gait speed as a measure of functional status in COPD patients
}

\author{
This article was published in the following Dove Press journal: \\ International Journal of COPD \\ 21 November 2014 \\ Number of times this article has been viewed
}

\section{Craig Karpman \\ Roberto Benzo}

Mindful Breathing Laboratory, Mayo Clinic, Division of Pulmonary and Critical Care Medicine, Rochester, MN, USA
Correspondence: Roberto Benzo Mindful Breathing Laboratory, Mayo Clinic, Division of Pulmonary and Critical Care Medicine, 200 Ist St SW Rochester, MN 55905, USA

Tel + I 507774056 I

Fax + I 5072664372

Email benzo.roberto@mayo.edu

Craig Karpman

Mayo Clinic, Division of Pulmonary and Critical Care Medicine, 200 Ist St SW,

Rochester, MN 55905, USA

Email karpman.craig@mayo.edu
Abstract: Chronic obstructive pulmonary disease (COPD) is a disease associated with dyspnea, fatigue, and exercise intolerance. The degree of functional debility and level of exercise capacity greatly influences quality of life and mortality in patients with COPD, and the measures of exercise capacity are to be an integral part of patient assessment but often not feasible in routine daily practice, resulting in likely suboptimal care. There is a need for simple ways to identify functional decline in the clinical setting in order to guide resources to preventive interventions or proper care, including palliative care. Gait speed, or measuring how long it takes for a patient to walk a short distance, takes very little time and space, and can serve as a candidate measure of physical function in COPD. Gait speed has been shown to be an indicator of disability, health care utilization, and survival in older adults. It is a simple, reliable, and feasible measure to perform in the clinic and has been promoted as the next vital sign, providing insight into patients' functional capacity. Gait speed is mainly determined by exercise capacity but reflects global well-being as it captures many of the multisystemic effects of disease severity in COPD rather than pulmonary impairment alone. It is an excellent screening measure for exercise capacity and frailty; in COPD, the usual gait speed (4-m course with rolling start) has been very accurate in identifying clinically relevant benchmarks of the 6 -minute walk test, poor $(<350 \mathrm{~m})$ and very poor $(<200 \mathrm{~m}) 6$-minute walk test distances. A specific cut-off point of $0.8 \mathrm{~m} \cdot \mathrm{s}^{-1}$ had a positive predictive value of $69 \%$ and negative predictive value of $98 \%$ in predicting very poor exercise capacity. The increasing evidence on gait speed is promising as a simple test that can inform the clinician about many important functional aspects of the COPD patient. Further work will likely show the strength of gait speed as a predictive marker of hospitalizations, re-admissions, and mortality. Instead of relying on the "eyeball test" regarding the patient's frailty or exercise capacity, a gait speed in its simplicity represents a much more solid assessment. Furthermore, repeat measures over serial clinic visits may show a pattern and further guide a change in therapy, whether it be medications, rehabilitation, or even initiation of palliative care discussions.

Keywords: emphysema, frailty, exercise capacity, palliative care, quality of life, physical activity

\section{Introduction}

Chronic obstructive pulmonary disease (COPD) is one of the main causes of morbidity and mortality worldwide and is expected to become the third cause of death and the fifth cause of disability-adjusted life years in 2020. ${ }^{1}$ COPD is a disease associated with dyspnea, fatigue, and exercise intolerance. The degree of functional debility and level of exercise capacity greatly influences quality of life and mortality in patients with COPD, and the measures of exercise capacity such as the 6-minute walk test (6MWT) and incremental shuttle walk test are believed to be an integral part of patient assessment. ${ }^{2}$ There 
is a need for simple ways to identify functional decline in the clinical setting in order to guide limited resources to preventive interventions or proper care, including palliative care.

\section{Functional assessment}

The value of measuring exercise capacity as a functional outcome in cardiopulmonary disease is indisputable. For example, the 6MWT as a measure of exercise capacity has been used to determine the effect of treatment interventions, ${ }^{3}$ transplant allocation, ${ }^{4}$ and prognosis.., 6 The $6 \mathrm{MWT}$ is also used for prognosis and as a measure of exercise tolerance in cardiac disease, particularly for pulmonary hypertension ${ }^{7}$ and heart failure. ${ }^{8}$ Routine monitoring of exercise capacity is compelling since a decline in 6MWT over time is a strong independent predictor of meaningful deterioration in severe COPD. ${ }^{5,9}$ While the measures of functional capacity like 6MWT are used regularly in pulmonary rehabilitation programs and research, they are not typically measured with daily clinic visits due to the time, equipment, and space requirements. ${ }^{10,11}$ Even when exercise capacity and daily physical activity are independently associated with morbidity and mortality in COPD, ${ }^{6,12-14}$ they are not routinely measured.

\section{Gait speed as a functional outcome measure}

Gait speed, or measuring how long it takes for a patient to walk a short distance, takes very little time and space, ${ }^{15}$ and can serve as a candidate measure of physical function in COPD. Gait speed has been shown to be an indicator of disability, ${ }^{16}$ health care utilization, ${ }^{17,18}$ and survival ${ }^{19,20}$ in older adults. Numerous studies have found that walking speed can predict important clinical outcomes. Community dwelling older adults are more likely to be hospitalized (relative risk 5.9 [95\% confidence interval $\{\mathrm{CI}\}, 1.9-18.5]$ ) and more likely to require a caregiver (relative risk 9.5 [95\% CI, 1.3-72.5]) if their gait speed was less than $0.7 \mathrm{~m} \cdot \mathrm{s}^{-1}$ when compared to their faster counterparts. ${ }^{17}$ The risk of hospitalization drops $40 \%$ for every $0.2 \mathrm{~m} \cdot \mathrm{s}^{-1}$ increase in gait speed. ${ }^{15}$ A gait speed of less than $0.5 \mathrm{~m} \cdot \mathrm{s}^{-1}$ is an independent predictor of falls (relative risk 1.4 [CI ,1.16-1.73]), ${ }^{21}$ but most importantly, in a large pooled cohort analysis, an increase in gait speed by $0.1 \mathrm{~m} \cdot \mathrm{s}^{-1}$ was associated $(0.88$ [95\% CI, 0.87-0.90]) with improved survival in older adults. ${ }^{19}$

Gait speed is a reliable and easy-to-perform measurement in a broad spectrum of disease populations, ${ }^{15,22-24}$ and has been promoted as the next vital sign, providing insight into patients' functional capacity. ${ }^{25}$ Measuring gait speed requires little space, time, or training, making it an attractive measure of exercise capacity for routine use in the clinic. Reference values have been published for the general population and are useful to interpret results of the test. ${ }^{26}$

Furthermore, gait speed is modifiable through strength training and rehabilitation, making it a potential marker of functional improvement as well as decline. ${ }^{6,9,27}$ Much like other vital signs, a one-time measure of gait speed may provide an objective measure of whole organism functioning and may signal physical function abnormalities requiring intervention. Alternatively, in severe COPD, a reduction in gait speed over time may herald short-term mortality, providing an opportunity to address advanced care planning and optimizing end-of-life care. ${ }^{6,9}$

\section{Gait speed in COPD literature}

The studies evaluating gait speed in COPD have several common themes. Short-distance gait speed (4-m course) has a strong correlation ( $r=0.77-0.78)$ with exercise capacity in COPD, as measured by either $6 \mathrm{MWT}^{28,29}$ or the incremental shuttle walk test. ${ }^{30}$ Gait speed is mainly determined by exercise capacity but reflects global well-being and captures the multisystemic effects of disease severity in COPD rather than pulmonary impairment alone (Figure 1).

Gait speed has significant associations with dyspnea, quality of life, and pulmonary function. ${ }^{19,28,30,31}$ Increasing dyspnea, based on a higher modified Medical Research Council dyspnea scale, is associated with a slower gait speed, with a correlation $(r)$ ranging from -0.52 to -0.55 . Patients with higher gait speeds have improved disease-specific healthrelated quality of life, higher percent predicted forced expiratory volume in one second, and higher diffusing capacity for carbon monoxide, but all of those factors are not as strong as dyspnea or exercise capacity in determining gait speed. ${ }^{28}$

Usual gait speed has been very accurate in identifying clinically relevant benchmarks of 6MWT, poor $(<350 \mathrm{~m})$ and very poor $(<200 \mathrm{~m}) 6 \mathrm{MWT}$ distances. A specific cutoff point of $0.8 \mathrm{~m} \cdot \mathrm{s}^{-1}$ had a positive predictive value of $69 \%$ and negative predictive value of $98 \%$ in predicting very poor exercise capacity. While the specific gait speed cut-off points do not predict an exact distance of 6MWT, they do provide a simple and inexpensive screening test for exercise capacity (an overall functional status) due to their strong negative predictive value. Gait speed fulfils other desirable criteria as a screening test: it is accurate, simple to perform, reliable, and inexpensive. ${ }^{25,32}$

Gait speed has also been found to significantly respond to pulmonary rehabilitation and decline over time in 


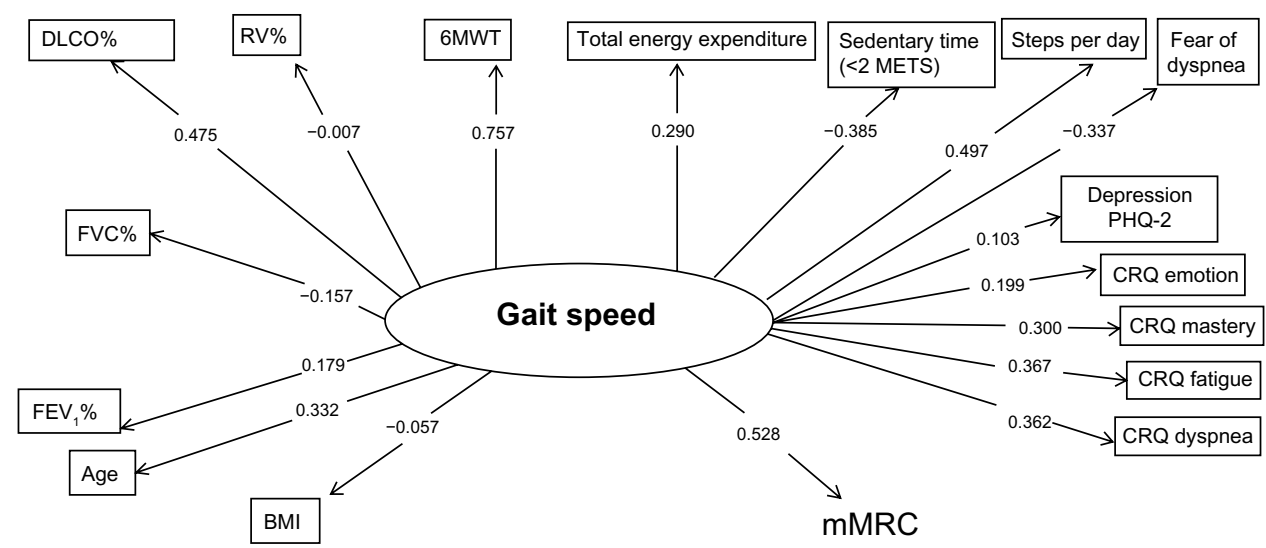

Figure I Gait speed construct: correlation $(r)$ between psychological and functional variables.

Abbreviations: 6MWT, 6-minute walk test; BMI, body mass index; CRQ, chronic respiratory questionnaire; DLCO, diffusing capacity of the lung for carbon monoxide; $\mathrm{FEV}_{\text {, }}$, forced expiratory volume in one second; FVC, forced vital capacity; METS, metabolic equivalent task; mMRC, modified Medical Research Council; PHQ-2, patient health questionnaire-2; RV, residual volume.

patients with COPD. ${ }^{33}$ Patients within the frailty category (gait speed $<0.8 \mathrm{~m} \cdot \mathrm{s}^{-1}$ ) are the ones whose gait speed was most responsive to pulmonary rehabilitation. The minimal clinically important difference of usual gait speed in patients with COPD seems to be between 0.08 and 0.11 $\mathrm{m} \cdot \mathrm{s}^{-1}$ defined consistently by anchor and distributionbased methods. ${ }^{33}$ Also, $0.11 \mathrm{~m} \cdot \mathrm{s}^{-1}$ represents half-standard deviation of gait speed in the COPD cohorts. Half-standard deviation is a recognized method to define a clinically important difference.

Gait speed is highly reliable and reproducible in COPD regardless of distance, instructed pace, or timing mechanisms. ${ }^{34}$ We recently demonstrated that usual gait speeds (walking at a comfortable/normal pace) and maximal gait speeds (walking as fast as you can safely, without running), measured by handheld stopwatches and automated timing systems, over two different distances (4- and 10-m courses) had exceptional reliability with interclass correlation coefficients ranging from $0.95-0.97 .{ }^{34}$ Similar excellent reliability was seen in other studies. ${ }^{23,30}$ Due to the variation found between stopwatches and automated timing systems, in particular when measuring maximal gait speed, we would recommend using one methodology consistently.

\section{The construct of gait speed}

Figure 1 graphically represents the relationship (correlation coefficients) between gait speed and numerous important physiological and functional clinical outcomes in COPD.

The most significant association is with exercise capacity measured by 6MWT. As reported and further detailed in this review, gait speed has excellent screening abilities for low $6 \mathrm{MWT}$ that enable the clinician to order a walking test when appropriate. Interestingly, gait speed is only modestly associated with total energy expenditure $(r=0.29)$, a measure that is related to total daily physical activity. However, it is more associated with specific activities like daily steps $(r=0.497)$ and inversely associated with sedentary time ( $r=-0.385)$.

Dyspnea measured by the modified Medical Research Council dyspnea scale, a cornerstone outcome in COPD, is significantly associated with gait speed $(r=0.528)$. Carbon monoxide diffusion capacity is significantly associated with gait speed in contrast to lung volumes or spirometry, suggesting that perhaps oxygen desaturation associated with poor diffusion capacity plays a role. Age is associated as expected and supported by extensive literature about the association of gait speed and the aging process. Emotions do not seem to be associated with gait speed as they are the other aspects of health-related quality of life (like dyspnea, mastery, and fatigue). In essence, the measure of gait speed may inform meaningfully the overall gestalt of the clinician about a patient with COPD.

\section{Implementing gait speed measurements}

A 4-m course is considered optimal for a field test ${ }^{35}$ balancing a distance short enough to be feasible in most clinical settings, but long enough to ensure measurement accuracy. The measurements need to be performed in a flat and unobstructed clinic hallway, and can be made even by nonprofessional staff ${ }^{19}$ with good reliability, even in frail patients or those with cognitive dysfunction. The most recent and validated methods described in COPD include a rolling start 4-m gait speed or a static start 4-m gait speed. ${ }^{30,34}$ For a rolling start, walks are performed with a 2-m rolling start where the participant is 
already walking as they enter the measuring area (Figure 2). Two cones are placed $8 \mathrm{~m}$ apart, and then an automated timing system or well defined marker is set up $2 \mathrm{~m}$ after the first cone and $2 \mathrm{~m}$ before the second cone, providing a 2-m acceleration zone, a 4-m timing area, and a 2-m deceleration zone. Patients are instructed to "walk at a comfortable and natural pace" from one cone to the other. Our group used rolling start to eliminate the reaction time, acceleration and deceleration components of the walk from the evaluation. For a static start, a protocol available from the National Institute on Aging $^{36}$ has been recently reported in a validation study in a large COPD cohort where a 4-m course is marked out with tape. A walk was demonstrated to each participant prior to starting the test, but participants themselves did not perform a practice walk. The participant was positioned with the toes just touching the start line. The following standardized instructions were given:

This is our walking course. I want you to walk just as if you are walking down the street down to the shops. Walk all the way past the other end of the tape before you stop. Ready ... begin.

Timing with a stopwatch started when the participant began to move, not on the command "begin". Timing was stopped when the participant's first foot completely crossed the 4-m line. In most studies, participants were allowed to use their normal walking aids (eg, cane or walker), and oxygen users were provided with extra-long tubing. While test-retest reliability is high, it is recommended to use a consistent methodology with the same distance, speed instructions, and timing mechanism all the time. Two trials of gait speed are recommended, with the fastest one to be used.

While the majority of studies measuring gait speed use a stopwatch, other options for timing mechanisms exist. The stopwatch timing method requires operators to be trained with extensive and detailed instruction. ${ }^{36}$ On the contrary, the automated system requires minimal training which could be completed in less than 5 minutes. ${ }^{34}$ In a tertiary care clinical setting where numerous clinical assistants are measuring the walking speed, a method that is easiest to train and with the lowest chance of variability between operators would be most effective in facilitating clinical implementation. Depending on financial resources and the ability to train personnel, using

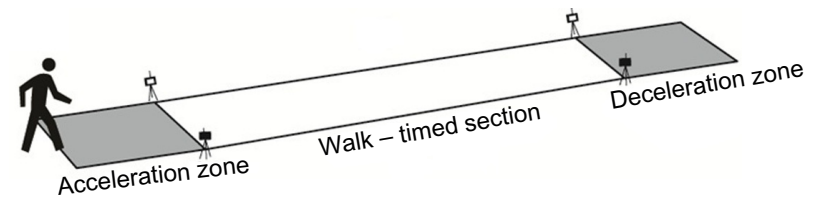

Figure 2 Gait speed measurement track. a stopwatch could also be a reasonable option for clinical use, but we would not recommend using a stopwatch or timer system interchangeably.

Short-distance gait speed already has its own unique assets, such as the ease of administration, and in the climate of changing health care and variable reimbursement, the use of gait speed may become more suitable than ever. Since gait speed is a fast and easy measure, it can be obtained on a routine basis allowing for physicians to trend change, and it may be the trend over months to a year which provides the most useful clinical information. ${ }^{9}$ Our group ${ }^{34}$ and others ${ }^{15}$ have shown that gait speed can be measured in a real-world clinic setting. Almost all patients found gait speed measurements prior to clinic visits as an acceptable evaluation, and there was minimal time/burden added to support staff when implementing gait speed as a vital sign.

\section{Limitation of gait speed}

While the 6MWT has been measured along with maximal oxygen consumption, similar evaluations have not been performed for short-distance gait speed. Unlike the 6MWT, gait speed has variability in methodology among the studies, ${ }^{19}$ leading to some difficulty in comparing results. The latter will resolve over time, as a unified technique is adopted. Regardless of the limitations, the ease of administration and the strong relationship with important outcome variables makes gait speed an important clinical marker.

\section{The future of gait speed in COPD}

Based on the strong relationship with measures of exercise capacity and other important outcomes in COPD, we believe that gait speed can be used as an indicator of overall wellbeing in the clinical setting. We suspect that over time, further work in the field will continue to show the strength of gait speed as a predictive marker in COPD and identify its ability to predict exacerbations, hospitalizations, readmissions, and mortality. Instead of relying on the "eyeball test" ${ }^{\prime 37}$ regarding the patient's frailty or exercise capacity, a gait speed measure can be used as an objective measure. Repeat measures over serial clinic visits may show a pattern and further guide a change in therapy, whether it be medications, rehabilitation, or even initiation of palliative care discussions.

\section{Acknowledgment}

This work was supported by the National Institutes of Health (Grant NIH NHLBI 1R01CA163293-01 [Principal Investigator: R Benzo]). 


\section{Disclosure}

The authors have no potential conflicts of interest to report.

\section{References}

1. Murray CJ, Lopez AD. Global mortality, disability, and the contribution of risk factors: Global Burden of Disease Study. Lancet. 1997;349(9063):1436-1442.

2. Vestbo J, Hurd SS, Agusti AG, et al. Global strategy for the diagnosis, management, and prevention of chronic obstructive pulmonary disease: gold executive summary. Am J Respir Crit Care Med. 2013;187(4): 347-365.

3. Paggiaro PL, Dahle R, Bakran I, Frith L, Hollingworth K, Efthimiou J. Multicentre randomised placebo-controlled trial of inhaled fluticasone propionate in patients with chronic obstructive pulmonary disease. International COPD Study Group. Lancet. 1998;351(9105):773-780.

4. Egan TM, Murray S, Bustami RT, et al. Development of the new lung allocation system in the United States. Am J Transplant. 2006; 6(5 Pt 2):1212-1227.

5. Pinto-Plata VM, Cote C, Cabral H, Taylor J, Celli BR. The 6-min walk distance: change over time and value as a predictor of survival in severe COPD. Eur Respir J. 2004;23(1):28-33.

6. Polkey MI, Spruit MA, Edwards LD, et al. Six-minute-walk test in chronic obstructive pulmonary disease: minimal clinically important difference for death or hospitalization. Am J Respir Crit Care Med. 2013;187(4):382-386.

7. Miyamoto S, Nagaya N, Satoh T, et al. Clinical correlates and prognostic significance of six-minute walk test in patients with primary pulmonary hypertension. Comparison with cardiopulmonary exercise testing. Am J Respir Crit Care Med. 2000;161(2 Pt 1):487-492.

8. Opasich C, Pinna GD, Mazza A, et al. Six-minute walking performance in patients with moderate-to-severe heart failure; is it a useful indicator in clinical practice? Eur Heart J. 2001;22(6):488-496.

9. Benzo R, Siemion W, Novotny P, et al. Factors to inform clinicians about the end of life in severe chronic obstructive pulmonary disease. $J$ Pain Symptom Manage. 2013.

10. American Thoracic Society. ATS statement: guidelines for the sixminute walk test. Am J Respir Crit Care Med. 2002;166(1):111-117.

11. Chetta A, Pisi G, Aiello M, Tzani P, Olivieri D. The walking capacity assessment in the respiratory patient. Respiration. 2009;77(4): 361-367.

12. Waschki B, Kirsten A, Holz O, et al. Physical activity is the strongest predictor of all-cause mortality in patients with COPD: a prospective cohort study. Chest. 2011;140(2):331-342.

13. Garcia-Aymerich J, Lange P, Benet M, Schnohr P, Anto JM. Regular physical activity reduces hospital admission and mortality in chronic obstructive pulmonary disease: a population based cohort study. Thorax. 2006;61(9):772-778

14. Watz H, Waschki B, Meyer T, Magnussen H. Physical activity in patients with COPD. Eur Respir J. 2009;33(2):262-272.

15. Studenski S, Perera S, Wallace D, et al. Physical performance measures in the clinical setting. J Am Geriatr Soc. 2003; 51(3):314-322.

16. Cesari M, Kritchevsky SB, Penninx BWHJ, et al. Prognostic value of usual gait speed in well-functioning older people - results from the Health, Aging and Body Composition Study. J Am Geriatr Soc. 2005; 53(10):1675-1680.

17. Montero-Odasso M, Schapira M, Soriano ER, et al. Gait velocity as a single predictor of adverse events in healthy seniors aged 75 years and older. J Gerontol A Biol Sci Med Sci. 2005;60(10):1304-1309.

18. Ostir GV, Berges I, Kuo YF, Goodwin JS, Ottenbacher KJ, Guralnik JM. Assessing gait speed in acutely ill older patients admitted to an acute care for elders hospital unit. Arch Intern Med. 2012;172(4):353-358.
19. Studenski S, Perera S, Patel K, et al. Gait speed and survival in older adults. JAMA. 2011;305(1):50-58.

20. Hardy SE, Perera S, Roumani YF, Chandler JM, Studenski SA. Improvement in usual gait speed predicts better survival in older adults. J Am Geriatr Soc. 2007;55(11):1727-1734.

21. Biderman A, Cwikel J, Fried AV, Galinsky D. Depression and falls among community dwelling elderly people: a search for common risk factors. J Epidemiol Community Health. 2002;56(8):631-636.

22. Peters DM, Fritz SL, Krotish DE. Assessing the reliability and validity of a shorter walk test compared with the 10-Meter Walk Test for measurements of gait speed in healthy, older adults. $J$ Geriatr Phys Ther. 2013;36(1):24-30.

23. Andersson M, Moberg L, Svantesson U, Sundbom A, Johansson H, Emtner M. Measuring walking speed in COPD: test-retest reliability of the 30-metre walk test and comparison with the 6-minute walk test. Prim Care Respir J. 2011;20(4):434-440.

24. Ries JD, Echternach JL, Nof L, Gagnon Blodgett M. Test-retest reliability and minimal detectable change scores for the timed "up and go" test, the six-minute walk test, and gait speed in people with Alzheimer disease. Phys Ther. 2009;89(6):569-579.

25. Fritz S, Lusardi M. White paper: "walking speed: the sixth vital sign". J Geriatr Phys Ther. 2009;32(2):46-49.

26. Bohannon RW. Comfortable and maximum walking speed of adults aged 20-79 years: reference values and determinants. Age Ageing. 1997;26(1):15-19.

27. Kongsgaard M, Backer V, Jorgensen K, Kjaer M, Beyer N. Heavy resistance training increases muscle size, strength and physical function in elderly male COPD-patients - a pilot study. Respir Med. 2004;98(10): 1000-1007.

28. Karpman C, Depew ZS, Lebrasseur NK, Novotny PJ, Benzo RP. Determinants of gait speed in chronic obstructive lung disease. Chest. 2014.

29. DePew ZS, Karpman C, Novotny PJ, Benzo RP. Correlations between gait speed, 6-minute walk distance, physical activity, and selfefficacy in patients with severe chronic lung disease. Respir Care. 2013;58(12):2113-2119.

30. Kon SS, Patel MS, Canavan JL, et al. Reliability and validity of the four metre gait speed in COPD. Eur Respir J. 2012

31. Ilgin D, Ozalevli S, Kilinc O, Sevinc C, Cimrin AH, Ucan ES. Gait speed as a functional capacity indicator in patients with chronic obstructive pulmonary disease. Ann Thorac Med. 2011;6(3): 141-146.

32. Herman CR, Gill HK, Eng J, Fajardo LL. Screening for preclinical disease: test and disease characteristics. AJR Am J Roentgenol. 2002;179(4):825-831.

33. Kon SS, Canavan JL, Nolan CM, et al. The 4-metre gait speed in COPD: responsiveness and minimal clinically important difference. Eur Respir J. 2014;43(5):1298-1305.

34. Karpman C, Lebrasseur NK, Depew ZS, Novotny PJ, Benzo RP. Measuring gait speed in the out-patient clinic: methodology and feasibility. Respir Care. 2014;59(4):531-537.

35. Guralnik JM, Ferrucci L, Pieper CF, et al. Lower extremity function and subsequent disability: consistency across studies, predictive models, and value of gait speed alone compared with the short physical performance battery. J Gerontol A Biol Sci Med Sci. 2000;55(4): M221-M231.

36. Assessing physical performance in the older patient: short physical performance battery [webpage on the Internet]. Baltimore, MD: National Institute on Aging; 2013. Short Physical Performance Battery. Available from http://www.grc.nia.nih.gov/branches/leps/sppb/. Accessed September 15, 2014

37. Rodes-Cabau J, Mok M. Working toward a frailty index in transcatheter aortic valve replacement: a major move away from the "eyeball test" JACC Cardiovasc Interv. 2012;5(9):982-983. 


\section{Publish your work in this journal}

The International Journal of COPD is an international, peer-reviewed journal of therapeutics and pharmacology focusing on concise rapid reporting of clinical studies and reviews in COPD. Special focus is given to the pathophysiological processes underlying the disease, intervention programs, patient focused education, and self management protocols.

This journal is indexed on PubMed Central, MedLine and CAS. The manuscript management system is completely online and includes a very quick and fair peer-review system, which is all easy to use. Visit http://www.dovepress.com/testimonials.php to read real quotes from published authors.

Submit your manuscript here: http://www.dovepress.com/international-journal-of-copd-journal 